\title{
Specialist medical training and the Calman report
}

\author{
Deserves and requires imaginative professional and managerial support
}

The group set up in response to the European Commission's view that Britain was infringing its directives on specialist recognition has published its report. ${ }^{12}$ The group recommends the introduction of a certificate of completion of specialist training, to be entered as "CT" in the medical register. The certificate is assumed to be equivalent to specialist recognition in other countries of the European Community and can be awarded to specialists from those countries (the register will specify which country awarded the certificate). The working group proposes an appeals mechanism; setting up one that is both statutory and independent would seem wise.

Award of the certificate requires the achievement of a definite educational end point, and most of the report is concerned with this. It proposes that the duration and content of specialist education should be clearly defined: the medical royal colleges will specify the curriculums, and the postgraduate deans will ensure that they are delivered. To facilitate this the colleges and deans will meet under the auspices of the chief medical officer.

The report suggests that the period of training, including general professional training, should not exceed seven years after full registration for most specialties. Many aspects of training will be enhanced, including assessment and feedback. Much needs to be done: most junior doctors believe that their training consists mainly of unsupervised service; moments snatched with books and journals; and unstructured, unreliable, and invalid feedback on the grapevine.

As proposed in the Short report ${ }^{3}$ and Achieving a Balance, ${ }^{4}$ the report recommends combining the registrar and senior registrar grades, which provides obvious advantages in continuity. Some specialties are already well advanced in implementing this, but others will experience serious difficulties. In itself, it will not reduce the length of training; the competitive bottleneck could, however, occur earlier.

The completion of training and the award of the relevant certificate will not guarantee appointment to a consultant post. A gap between completion of specialist training and a consultant appointment is therefore likely. Various principles and strategies for dealing with this gap are suggested, but the anxiety expressed by Brearley ${ }^{5}$ is not adequately addressed. He argued that those in this gap would in fact be subconsultants and the NHS would have no obligation to fund comprehensive continuing training for them.

Like so many others before, the working group rejected formalising a subconsultant grade, suggesting that it would lead to a two tier service for patients. This faith in the homogeneity of consultants' standards is understandable, if somewhat at variance with the evidence. ${ }^{6}$ The corollary of insisting that formal standards must be reached before appointment to the consultant grade is that they should be maintained afterwards, but the report, unsurprisingly, does not address the need for their formal assessment.

For many reasons, the only coherent solution is to expand substantially the numbers of consultants. Firstly, given the time spent by juniors in training and the time spent by consultants in training them (and, hopefully, in learning how to train and assess), more doctors will be needed. Secondly, if wasteful medical misemployment or even unemployment is to be avoided the top tier of the hierarchy needs expanding. Thirdly, patients and management justifiably expect more care to be delivered by fully trained specialists. And, lastly, doctors currently train for substantially longer periods than the minimum recommended periods of training: lack of consultant posts therefore seems to be the main factor in lengthening training, and reducing training will depend on creating more posts.

The numbers of consultant posts must increase both absolutely and relative to the numbers of junior posts, and the expansion must be in response to existing workload. This requires a radical reappraisal of consultant work as it implies a shift from a predominantly consultant led to a predominantly consultant provided service. Neither precedent nor the mechanisms indicated in the report are encouraging. Particularly discouraging - indeed, ominous-is the suggestion in the chief medical officer's covering letter to the profession that "the department will be looking for a method to implement the recommendations which does not increase paybills beyond existing plans." 7 Finance is not the only factor that has militated against successful manpower planning, and it may not even be the most important, but consultant expansion cannot and will not happen without extra investment.

The report indicates that Achieving a Balance is being reevaluated, which is good news. For example, one of the suggestions is for the conversion of registrar into consultant posts-first suggested by the registrars group of the Central Committee for Hospital Medical Services in 1952. Achieving a Balance identified a mechanism for this ("the Grabham ratchet"), and it would be interesting to know how often this has been used-not often, one suspects; presumably consultants are unenthusiastic at having their registrars replaced by consultants. 
There has been a vision that the service would be mainly consultant provided since the Spens Committee report in $1948 .^{8}$ Through several reports since, that vision has remained unaltered and unachieved. ${ }^{3410}$ Although there have been some modest variations, the ratio of junior doctors to consultants now is much the same as it was at the inception of the health service. ${ }^{11}$ The working group's report makes little reference to the strategic plans for the NHS or to the reforms. Both will affect the need for doctors and how consultants will be expected to work. One of the reasons why manpower planning has failed is that it has never been integrated with other NHS plans. This has left most medical activity "unmanaged" and ensured a continuing contradiction between professional aspirations to enhance the medical career structure and attempts to manage the health service in ways that accord primacy to other NHS goals. ${ }^{12}$

Why this happens warrants critical evaluation. For a profession that places such emphasis on its ability to examine evidence scientifically it is remarkable that it should manage its own affairs on the basis of opinion rather than testable fact. Dr Alistair Scotland, who was a member of the working party, asked some pertinent questions about consultant working patterns in $1990 .{ }^{13} \mathrm{His}$ questions remain unanswered, and, unless they are, Calman's report will not be successful as consultants at local level again react instinctively and protectively against changes in their working patterns and increases in their number. Similarly, ministers and managers may refuse to implement plans that are expensive and do not seem linked to the overall strategic intent and direction of the health service.
Consultation on the report continues until July. There may be more work to do-as some claim-but it would be a great pity if Calman's report were to go the way of the Spens, Platt, Todd, and Short reports and fail on the rocks of unimaginative professional resistance and unimaginative managerial restraint.

Gwent Community NHS Trust,

Llanfrechfa,

Gwent NP44 8YN

Canterbury and Thanet NHS Trust,

St Martin's Hospital,

Canterbury,

Kent CT1 1TD

1 Department of Health. Hospital doctors: training for the future. The report of the working group on specialist medical training. London: $\mathrm{DoH}, 1993$.

Beecham L. Specialist training may be overhauled. BMF 1993;306:1287-8.

3 Social Services Committee. Fourth reporn. Medical education with special reference to the number of doctors and their career structure in hospitals. London: HMSO, 1981. (Short report.)

4 Department of Health. Hospital medical staffing - achieving a balance. Plan for action. London DoH, 1987.

5 Brearley S. Specialist medical training and Europe. BMY 1992;305:661-2.

6 Andersen TF, Mooney G, eds. The challenges of medical practice variations. London: Macmillan, 1990.

7 Department of Health. Dear colleague. Consultation on report of working group on specialist medical education. London: DoH, 1993. (KK/00923.04.)

8 Interdepartmental Working Committee on the Remuneration of Specialists. Report. London: HMSO, 1948. (Spens report.) (Cmnd 7420.)

9 Joint Working Party on the Medical Staffing Structure in the Hospital Services. Report. London: HSO, 1961. (Plat the Mepic 10 Royal Commission on Medical Education. Report. London: HMSO, 1968. (Todd report.) (Cmnd

11 Ham C. Policy making in the National Health Service. London: Macmillan, 1981.

12 Long AF, Mercer G. Health manpower: planning, production and management. London: Croom Helm, 1987

13 Scotland A. Consultant oligarchy or workers' cooperative? Br $f$ Hosp Med 1990;44:152

\section{Annual reports of directors of public health}

\section{We need to agree their aims and evaluate their effectiveness}

Annual public health reports, to be written by directors of public health, were reintroduced following the Acheson report. ${ }^{1}$ They were designed to "Inform each district health authority ... about the health of the population for which they are responsible and ... to be an integral component of the health planning and contracting cycle."2 Acheson suggested that the report should be "based on the professional work and judgment of the director of public health and ... make an important contribution to the accountability of the health authority to the people they serve."1

Most directors of public health have now produced several annual reports, and it may be time to assess how well these have measured up to the original aims, especially since the NHS has changed dramatically since the Acheson report. Producing reports is costly in terms of both money and manpower, and so far there is little evidence of their effectiveness. Those assessments that have been undertaken have been predominantly concerned with the contents of the reports. ${ }^{34}$ A specific example is the King's Fund initiative, which, despite a lack of criteria for assessing even their content, offers a prize for the "best."

The Faculty of Public Health Medicine has suggested several functions that could be served by the annual public health report; these include challenging conventional beliefs about health and disease and identifying opportunities for health authority action. ${ }^{2}$ There is no evidence, however, that these functions have been widely accepted either by directors of public health or by their health authorities, and no attempt has been made to undertake a widespread review of the impact of reports measured against such goals.

In the context of the reformed NHS there seem to be three components to the objectives of annual public health reports as originally envisaged by Acheson': (a) that annual reports should influence commissioning and be integral to the strategic planning programme; $(b)$ that they should reflect the independent judgment of the directors of public health; and (c) that they should enhance the accountability of health authorities to the population they serve.

The common dilemma arising from such objectives is how directors of public health can maintain an independent view in their reports while at the same time ensuring that reports are "owned" by commissioning authorities. If authorities do not feel they own the report they are less likely to adopt its recommendations and thus the report is less likely to be effective. The principle that a board member with corporate responsibilities should produce an independent report is unusual and may not be readily accepted by other directors of health authorities. ${ }^{5}$ Because health authorities normally finance the annual report they may also be reluctant to relinquish all editorial control.

Against this is the belief that directors of public health must maintain the right to produce an independent report to help fulfil their role as advocate for the public health. ${ }^{46}$ Such autonomy is essential to ensure that public health issues outside the health authority's commissioning priorities are aired and that a broader view is offered of the way in which the 